\title{
ARMAGH OBSERVATORY -HISTORIC BUILDING INFORMATION MODELLING FOR VIRTUAL LEARNING IN BUILDING CONSERVATION
}

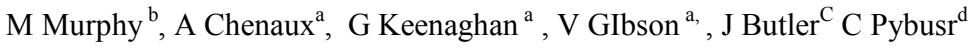 \\ Dublin Institute of Technology, alain.chenaux@dit.ie \\ ${ }^{\mathrm{b}}$ VBE Lab Ireland, virtualbuildinglab@gmail.com \\ ${ }^{c}$ Armagh Observatory, john.butler@gmail.com \\ ${ }^{\mathrm{d}}$ Carleton University, cailenpybus@cmail.carleton.ca
}

\section{ABSTRACT:}

\section{Commission II, WG VI/4}

In this paper the recording and design for a Virtual Reality Immersive Model of Armagh Observatory is presented, which will replicate the historic buildings and landscape with distant meridian markers and position of its principal historic instruments within a model of the night sky showing the position of bright stars. The virtual reality model can be used for educational purposes allowing the instruments within the historic building model to be manipulated within 3D space to demonstrate how the position measurements of stars were made in the 18th century. A description is given of current student and researchers activities concerning on-site recording and surveying and the virtual modelling of the buildings and landscape. This is followed by a design for a Virtual Reality Immersive Model of Armagh Observatory use game engine and virtual learning platforms and concepts.

KEY WORDS: HBIM, Digital Heritage Documentation, Laser Scanning, Photogrammetry, Heritage Management, Virtual Learning Environments

\section{ARMAGH OBSERVATORY}

The observatory at Armagh in Northern Ireland was founded in 1790 by the Church of Ireland Archbishop, Richard Robinson as part of his wider scheme to develop the fabric and institutions of the city following a prolonged period of strife and neglect. Conscious of the value of education, he envisaged that the Observatory would in due course form a part of a new university but, sadly, through a combination of unforeseen circumstances, including: his death in 1794, a time limit on his legacy, the 1798 rebellion and the subsequent Act of Union in 1801, his plans were never implemented. Nevertheless, the Observatory, as an early part of the scheme had already been incorporated by an Act of the Irish Parliament at the time of Robinson's death and consequently survived (Bennett, 1990).

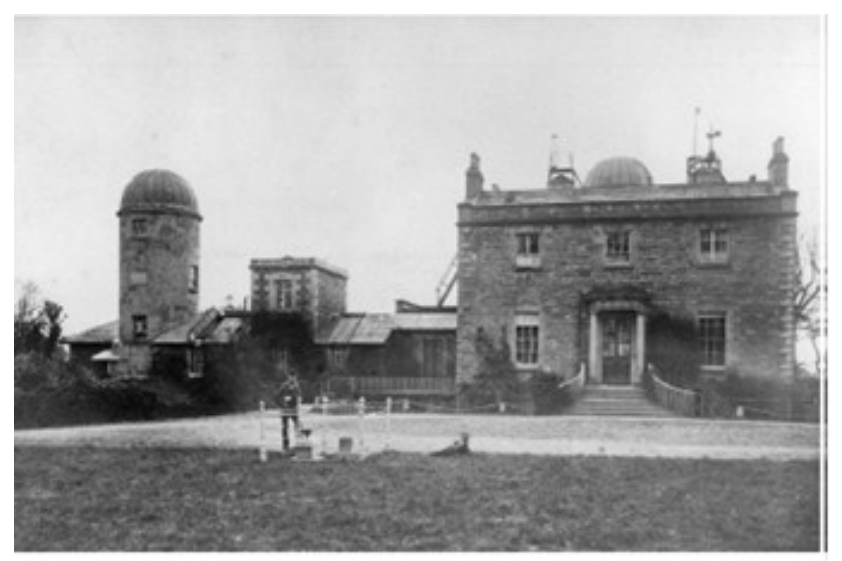

\section{Figure 1: Armagh Observatory}

\section{LEARNING PROGRAMME}

Students who are studying the module in Building Conservation in the Dublin Institute of Technology undertake the digital recording and $3 \mathrm{D} \mathrm{CAD}$ modelling of a chosen historic structure and its environment each semester. The emphasis is on learning by doing so low cost accessible recording and modelling tools are used by the students. In the case of the Armagh Observatory the aim of the proposed project was to create a 3D computer based model of the observatory its instrument positions and the location of the meridian markers by building a virtual terrain model and virtual building model placed in the terrain. The final result as a full virtual model of the building and its markers can then be employed for simulating the instruments in their position in the observatory and earths meridian used to measure declination, the angle between the star and the celestial equator.

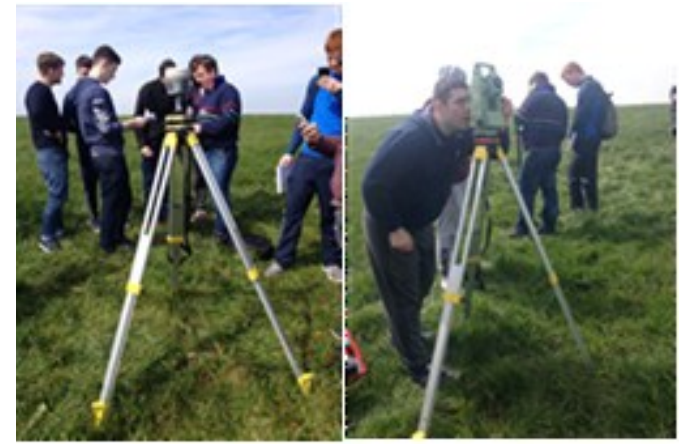

Figure 2: Student Site Survey at the Observatory 
The range of tools that were chosen for recording and modelling was based on low cost and easy to use technologies. The recording tools consisted of total station, 3D Disto and GPS. The historic drawing was complimented with site measurements and the first models were built in 3D CAD. Initially a terrain model was built as the meridian markers are located some miles from the observatory. The position of the markers was located onto the terrain model. The observatory was constructed from the site surveys and historic drawings and was constructed using the principles of HBIM. Architectural objects are located onto the survey geometric framework to create the virtual building model.

\section{STUDENT HISTORIC BUILDING INFORMATION MODELLING (HBIM) PROJECT OF ARMAGH}

Historic Building Information Modelling (HBIM) is an extension of advanced 3D CAD Building Information Modelling for the physical and knowledge management and conservation of architectural heritage. HBIM involves the digital recording of historical buildings using remote sensing (laser scanning, digital photogrammetry) or combinations of digital surveying and manual techniques. The acquired survey data is then processed improving the data organisation and adding intelligence using BIM software platforms. Because of the difficulties in accurately representing the variety of complex and irregular objects occurring in historic buildings existing BIM libraries of parametric objects need to be rebuilt and coded. In addition as the building exists and is represented by a remotely sensed model, systems to map the intelligent library objects onto digital or other survey data were also developed (Fai et al. 2011; Murphy, McGovern \& Pavia 2009; Dore \& Murphy 2014). The following figures illustrate the modelling of the observatory from historic drawing and site surveys.

The initial images are $3 \mathrm{D}$ replications of the landscape incorporating the observatory and the meridian markers,

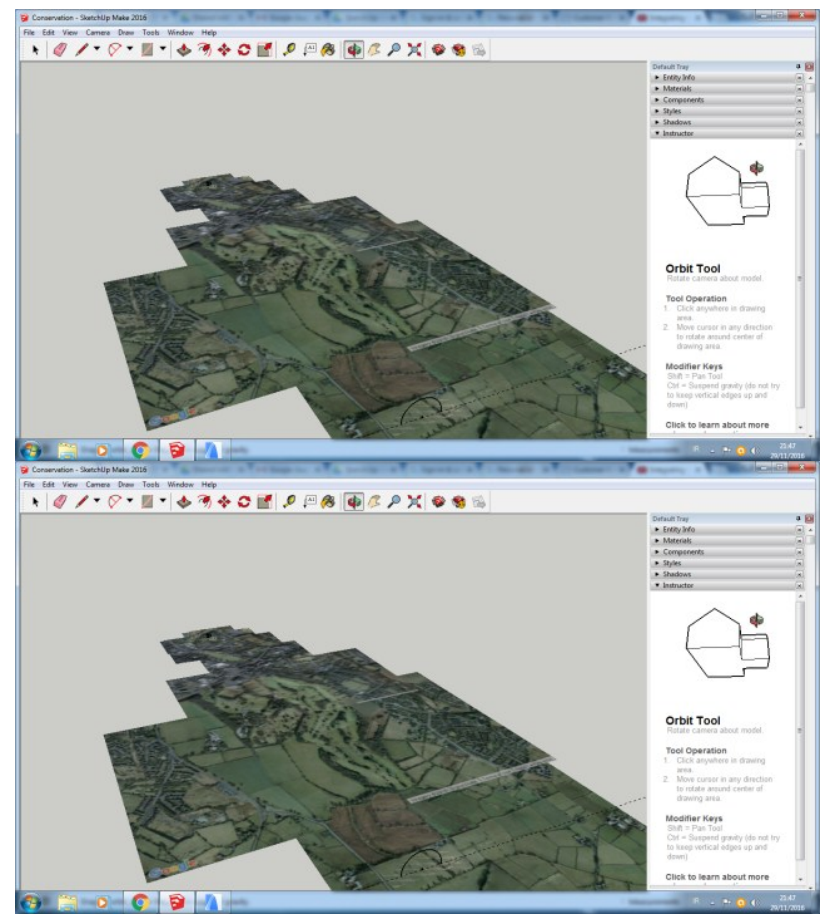

Figure 3: Landscape Virtual Model
The model is extracted from Google earth as a KMZ file a placemark file used by Google Earth. Keyhole Markup language Zipped (KMZ) is a compressed version of a KML (Keyhole Markup Language) file (Apolo Mapping). The KMZ files will open in Google Earth related products and must follow a conversion to insert $\mathrm{s}$ in HBIM.

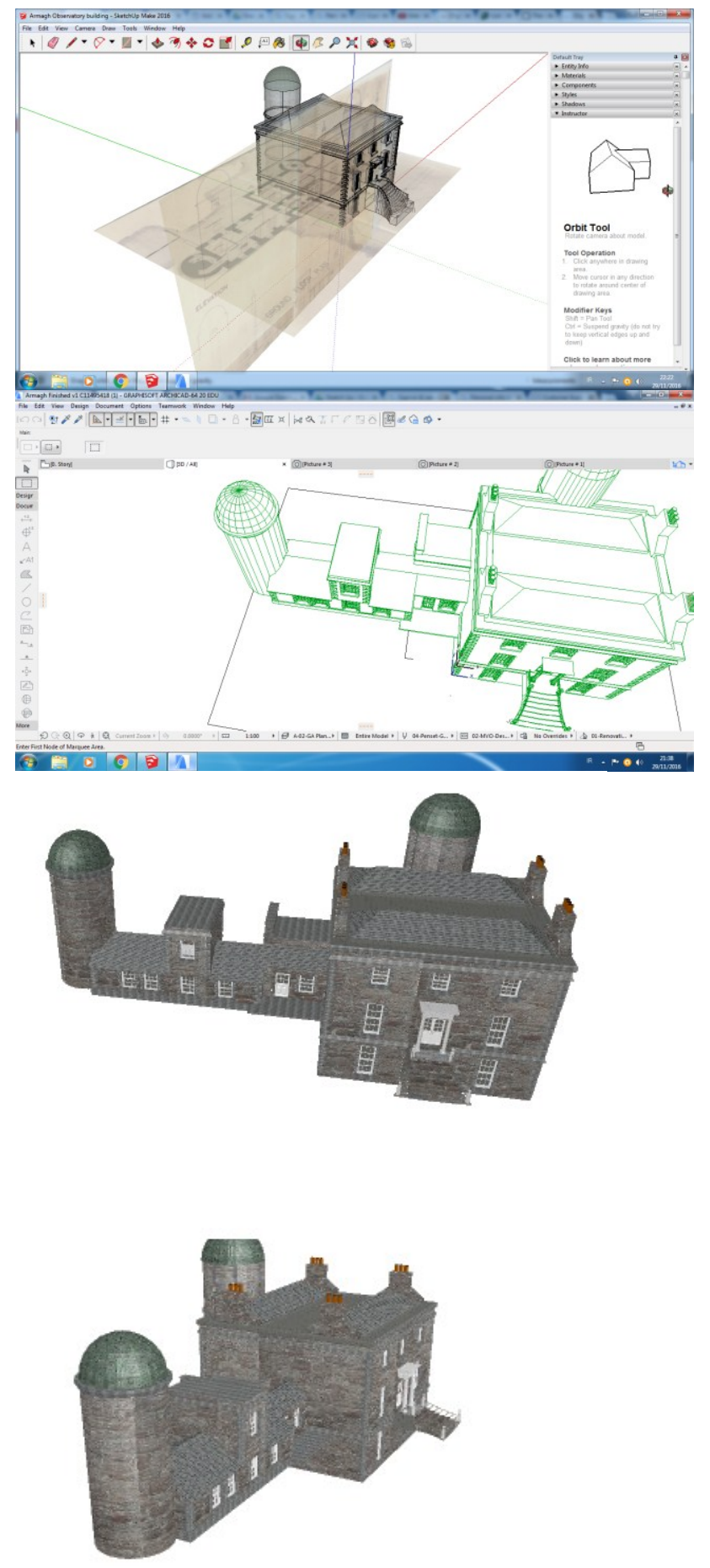

Figure 4: Historic Building Information Model of Armagh Observatory

The model was constructed in Sketchup and ArchiCAD using the historic drawings and the site measurements taken to date. 
The 3D model is made up from by combining 3D library objects which represent the architectural elements such as walls, floor, windows, roof and other building elements.

\section{THE MERIDIAN MARKS}

An essential requirement for the measurement of both celestial coordinates is the delineation of the meridian, that is the exact north-south line passing through the instrument. To keep the instruments accurately aligned to the meridian it was common practice to observe a point on the horizon at dusk which indicated the exact location of the meridian. If there was any error in the alignment of the instrument, it would be corrected before observations begun. The meridian was defined to about 1 second of arc accuracy, which is about the limit imposed by the accuracy of the instruments and the stability of the atmosphere. For checks during hours of darkness, when the meridian marks could not be seen, local illuminated marks were set up in the Observatory grounds.

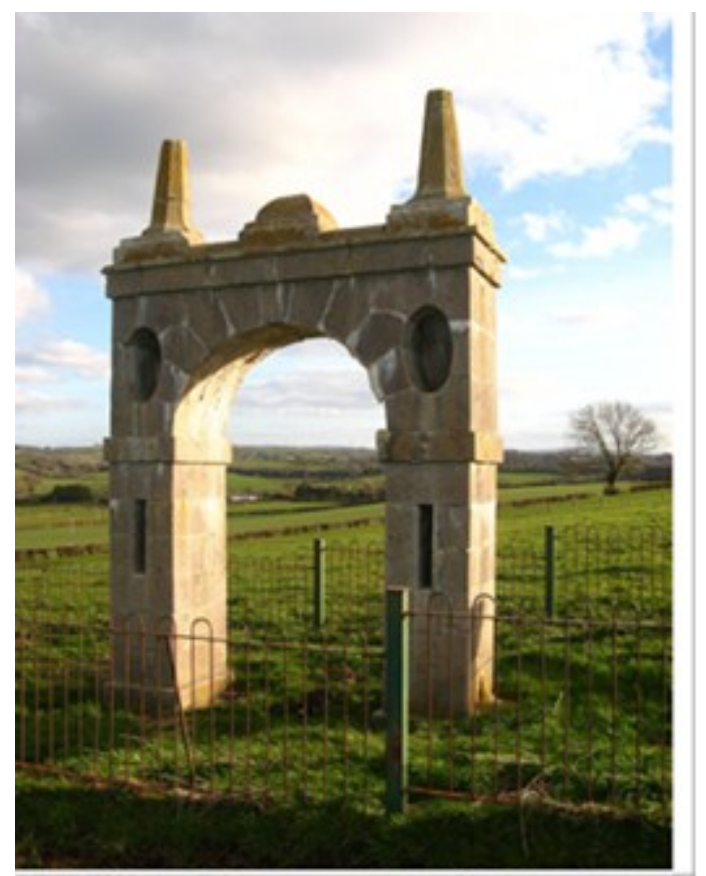

Figure 5: The Meridian Mark at Tullyard for the Transit Instrument from the north-west.

Note the elliptical holes (subsequently blocked) which formed the first stage of alignment and the vertical slits for the second stage. Metal disks mounted on the pinnacles on the top of the arch provided the third stage.

The construction of accurate meridian marks was believed in the late 18th and early 19 th centuries to be essential for precise measurement of stellar coordinates and individual surviving marks can be found for both Greenwich and Paris Observatories.

Armagh which has three surviving meridian markers the decline in the population of Ireland in the 19th century and the resultant lack of growth of the City of Armagh would be contributory factors in the survival of the marks here.

In total, there have, at some time or other, been meridian marks at seven different locations near Armagh . They are referred to here by the names of the townlands in which they were situated.
There were three at Tullyard, close to Grange, north of the City, two at Corkley, near Darkley to the south, one at Ballyheridan south of the Palace and the other at an uncertain location in the Palace Demense. Details of their location, their approximate construction date, for which instrument they were used and the period of use, are given in Table 1. A short description of each meridian mark follows.

\section{RECORDING MERIDIAN MARKERS USING GPS}

The survey data was recorded in the WGS84 (ETRF89) geodetic coordinate system using a Trimble R10 GNSS receiver. The receiver was operated in Network Real-Time Kinematic mode, whereby the GNSS receiver is connected through a mobile connection to a network of fixed base stations (Trimble VRS system), which provides real-time corrections for major sources of errors.

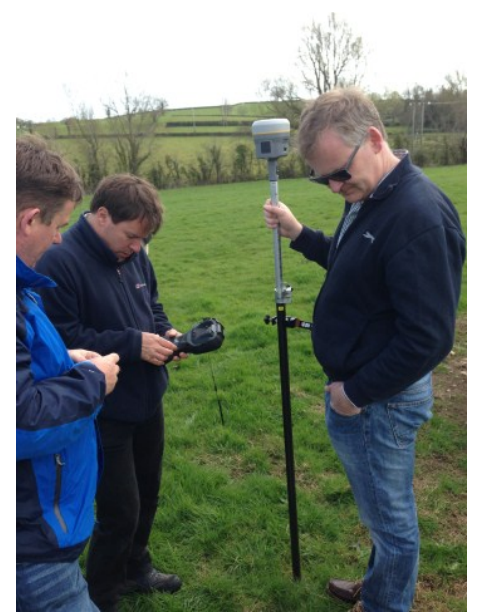

\section{Figure 6: GPS measurements}

An accuracy of a few centimetres has been typically reported for both planimetric and orthometric height measurements using this system in Ireland (e.g. Martin \& McGovern 2012). Once all data was collected, it was exported from the data logger into a comma delimited format (csv) text file. To unify the coordinate systems with historical data, the GNSS data was converted to the Irish National Grid using the coordinate transformation software Grid InQuest, which is available on both Ordnance Survey Ireland and Ordnance Survey Northern Ireland websites (Figure 1).

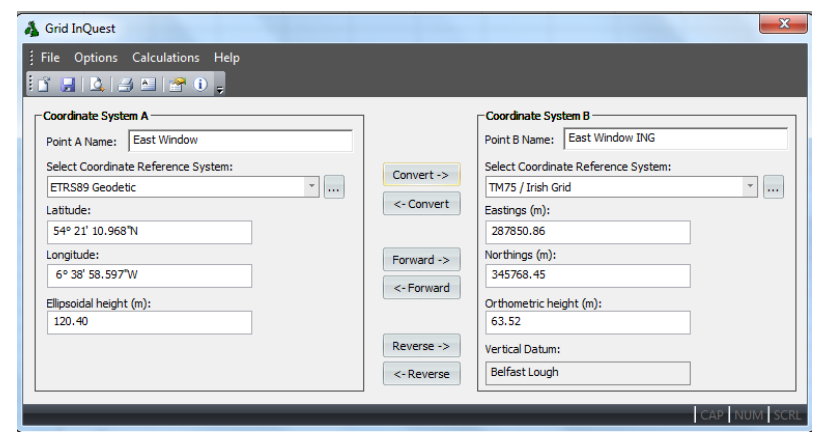

Figure 7: Grid Inquest for coordinate system transformation 
The whole data is presented in Table 1. For the Meridian Room at the Observatory, measurements were taken from just outside the Meridian room, on each side of the room's two windows, with the receiver positioned as close as possible along the meridian's line. As an initial check, an additional measurement was also recorded over an Ordnance Benchmark (OBM) with known coordinates below the Troughton Dome.

Table 1: Survey data in WGS84 and Irish National Grid coordinates

\begin{tabular}{|c|c|c|c|c|c|c|}
\hline & \multicolumn{3}{|l|}{ WESBA } & \multicolumn{3}{|c|}{ Irish Nationel Grid (fIMG) } \\
\hline & Longitude & Lotitude & Height & Easting: & Morthings: & Height \\
\hline \multicolumn{7}{|l|}{$\begin{array}{l}\text { Meriden Room st Observatory- } \\
\text { Morth Side }\end{array}$} \\
\hline East Window (neare:t 1827 dome) & $54^{\circ} 21^{\circ} 10.9699^{\prime}$ & $6^{\circ} 38.58597-w$ & 120.4 & 287850.86 & 345768.48 & 5136 \\
\hline West Window & $54^{\circ} 21^{\prime} 10.969^{\circ} \mathrm{W}$ & $6^{\circ} 38^{-59092^{-W} w}$ & 117.17 & 287841.91 & 34576830 & 6029 \\
\hline $\begin{array}{l}\text { OS Mark bedow the Troughton } \\
\text { Dome }\end{array}$ & $54^{\circ} 21^{\prime} 10.968 \mathrm{~N}$ & $6^{\circ} 38^{\prime} 58597-w$ & 11421 & 287850.86 & 345768.45 & 6052 \\
\hline \multicolumn{7}{|l|}{ Tullyards } \\
\hline Southride & $54^{\circ} 22^{2} 21054^{-1} \mathrm{~N}$ & $6^{\circ} 3858676-w$ & 11421 & 287807.90 & 34793535 & 5535 \\
\hline Northside & $54^{\circ} 22^{\prime} 21097 \mathrm{~N}$ & $6^{\circ} 3858675-w$ & 11424 & 287807.93 & 347936.69 & 5738 \\
\hline \multicolumn{7}{|l|}{ Bellyheriden Meridien Merk } \\
\hline Northride & $54^{\circ} 19^{3} 34.9677 \mathrm{~N}$ & $6.3858 .967 \mathrm{~W}$ & 133.4 & 28790106 & 342800.15 & 76.49 \\
\hline Southside & $54^{\circ} 19^{\prime} 35.0533^{-N}$ & $6^{\circ} 38$ 58.99r-W & 1362 & 287900.46 & 342802.80 & 79.29 \\
\hline
\end{tabular}

Measurements at Tullyards (Figure 2) and Ballyheridan (Figure 3 ) could only be observed at the base of the monument; in both cases, a measurement was taken on each side of the monument (i.e. South side and North side of the monument), on positions estimated as being as close as possible to the alignment of the meridian.

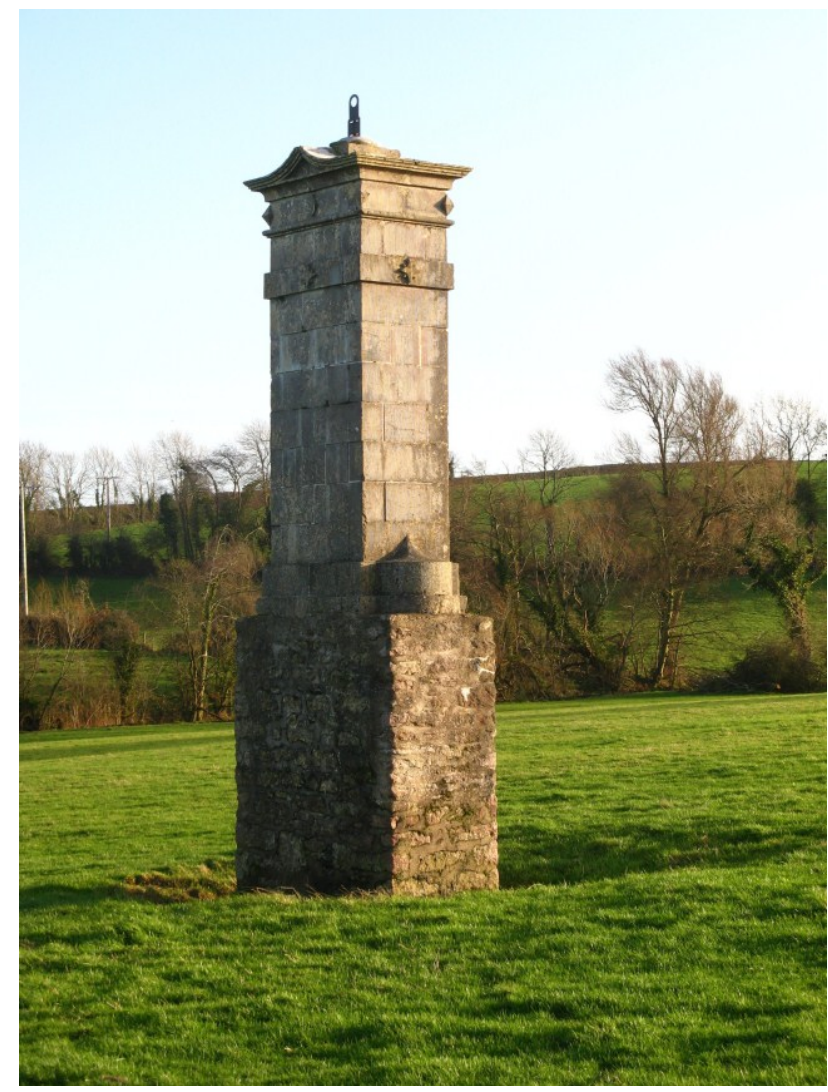

Figure 8: The Southern Meridian Mark for the Transit Instrument at Ballyheridan from the north-west. The stone base and the metal fiducial mark on top were renovated in 1999.

Virtual Reconstruction -Digital Photogrammetry

Most modern scanning systems are fitted with a CCD (chargecoupled device) digital camera and the image data that is captured can be used to colour the product of the laser scan survey data (the point cloud). Digital photogrammetry is based on hardware for data capture such as SLR digital cameras and thermal imagers or in some cases off-the-shelf cameras. The acquired data is then processed, fused and integrated using state-of-the-art photogrammetric and computer vision algorithms which are readily available with software platforms Autodesk Re-Cap and 123D-Catch, Agisoft Photoscan, Microsoft Photosynth, Micmac, Pix4D, etc. Geo-referencing Image-based approaches are gaining momentum because they are much more cost effective than laser-based or structured light scanning methods. In digital photogrammetry stereo images are captured with multiple camera positions, pixel matching is used to locate similar points on the images and ray tracing to locate the camera positions. The geometric calculation of intersecting rays of light and the base line distance between cameras provides sets of triangles. From the triangulation process a point cloud is produced, locating the xyz points of the object. The point cloud is processed similar to laser scanning by meshing and texturing. The triangulation principle or bundle adjustments coordinates of multiple points on the object are measured in different images and are simultaneously used to calculate the 3D object coordinates by predicting the intersecting rays (Remondino et al. 2006;2011).

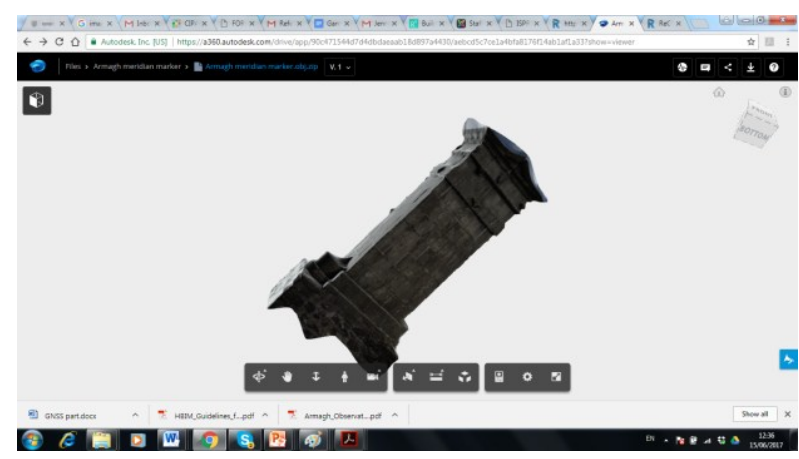

Figure 9: Photogrammetric Virtual Reconstruction of the Southern Meridian Mark in RECAP

\section{NEXT PHASE - VIRTUAL REPRESENTATION OF OBSERVATORY INSTRUMENTS}

In common with other observatories at this time, its principal activity for the next 90 years was the measurement of the positions of stars and planets. The Instruments and Clocks employed at Armagh Observatory The measurements of the celestial coordinates, right ascension and declination, were usually, in the late 18th century, made separately with two different instruments. Declination, the angle between the star and the celestial equator was commonly determined with a quadrant set up to observe in the meridian. In practice, however, rather than measure the declination directly, it was normal to measure the zenith distance and convert to North Polar Distance, the converse of declination. As techniques developed 
in the 18th century, larger, more accurate and less portable instruments were designed and, for stability and protection from the elements, they were placed in specially constructed buildings. One such improvement was the Mural Circle, an instrument that was fastened to a wall exactly in the north-south plane. Examples are to be seen at Greenwich, Oxford and many other observatories including Armagh.

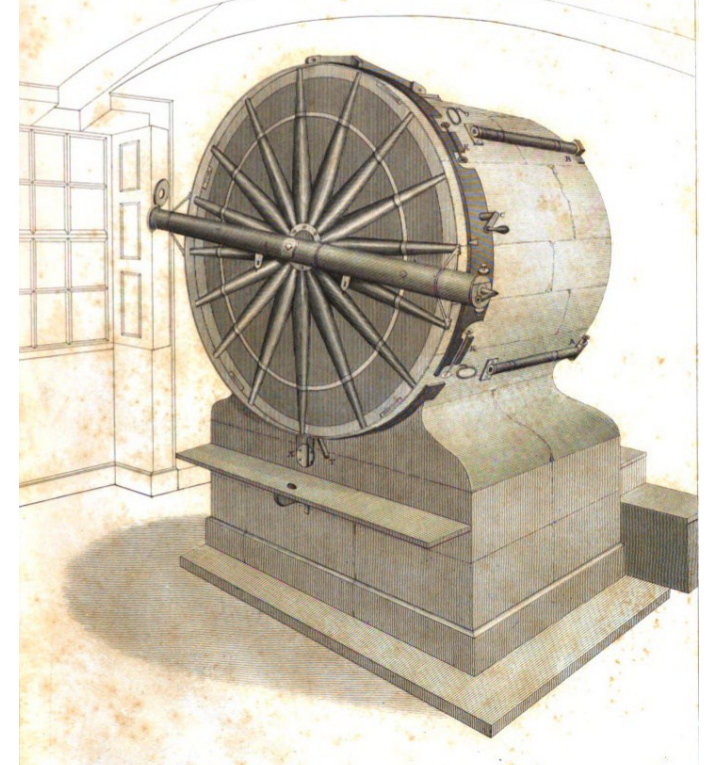

Figure 10: The Jones Mural Circle at Armagh Observatory in its original configuration

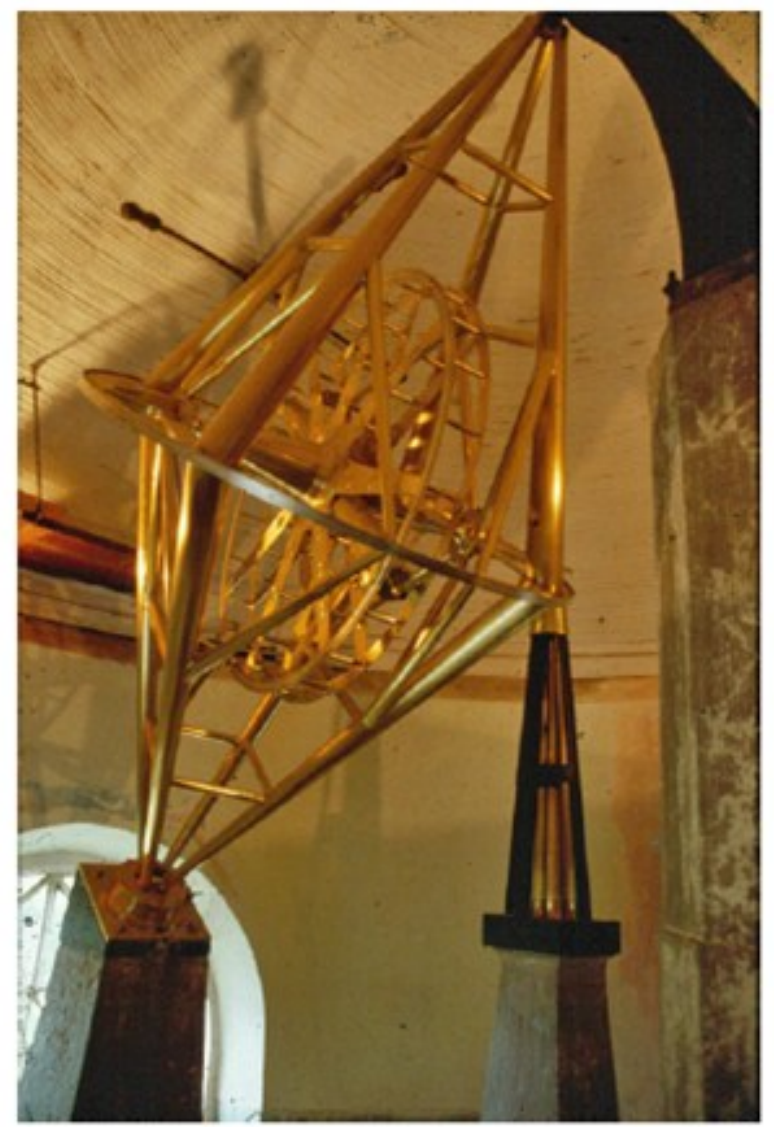

\section{Figure 11: The Troughton Equatorial Telescope}

The other coordinate that astronomers needed to measure was the celestial longitude or right ascension. In principle, all that was required was to time the transit of the object (star, Sun or planet) as it crossed the meridian using an accurately mounted telescope and a reliable clock. As the star crossed the meridian in the telescope (marked with a crosswire), the exact time was noted, usually to a precision of about one tenth of a second. This was accomplished by interpolating between the ticks of a clock rated to sidereal time which was placed nearby.

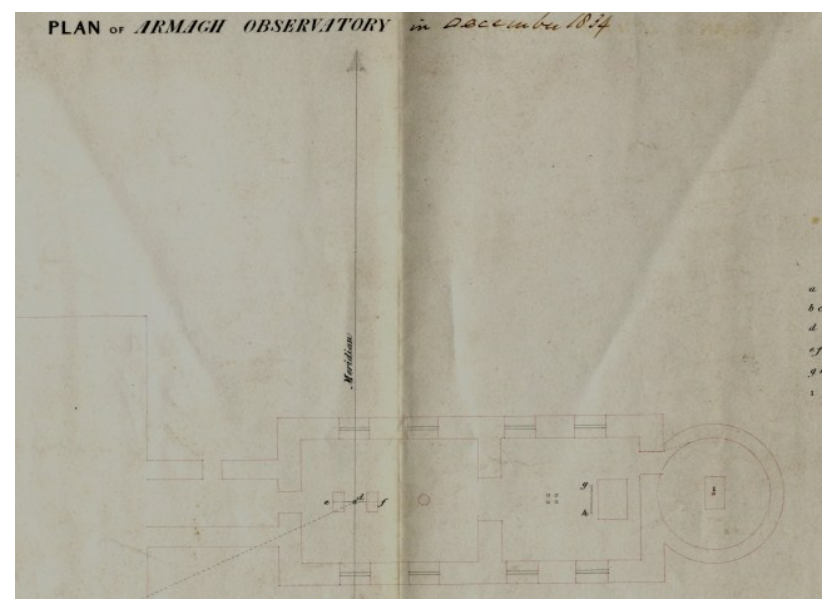

\section{Figure 12: Observatory Plan Showing Location of} Meridian

\section{BUILDING OBSERVATORY INSTRUMENTS AS VIRTUAL LEARNING OBJECTS (VLO)}

The aim of this proposal is to create an open access Virtual Reality Immersive Model of Armagh Observatory replicating the historic buildings and the earth and celestial landscape with distant meridian markers and position of its principal historic instruments within a model of the night sky showing the position of bright stars. The virtual reality model can be used for educational purposes allowing the instruments within the historic building model to be manipulated within 3D space to demonstrate how the position measurements of stars were made in the $18^{\text {th }}$ century. It is intended to reconstruct the observatory instruments as Virtual Learning Objects which means that students and public can interact with the virtual replication of the historic instruments, buildings and landscape.

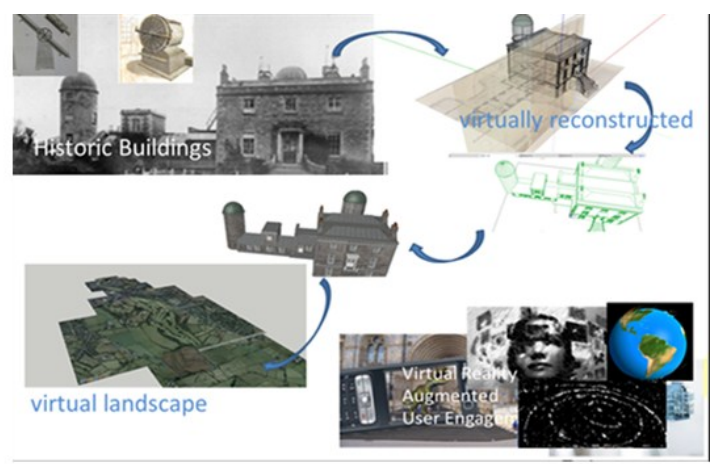

Historic Buildings and instruments are virtually reconstructed placed in a virtual landscape and presented within an Immersive virtual reality learning environment

Figure 13: Virtual Reconstruction of Armagh 
Similar to object orientated programming, Learning Objects systems (LO) exist as elements or entities in digital format and can be reused as content in WEB based learning environments. The main computing elements are metadata standards and system specifications such as levels of scale, level of detail of data and cross platform interoperability. The types of digital resource that can be reused to support learning include images or photos, live data feeds, live or pre-recorded video or audio snippets, text, animations, and web-delivered applications such as a Java applet, a blog, or a web page combining text, images and other media (Wiley, 2000). Learning Objects (LO) as knowledge based object are self-contained and reusable and described by their meta-tags which include their history, meaning, quality and destination. LO elements are units which make up the content and the LO can be singular or a combination of elements. Interactivity allows the LO by the action of a user to refer to other internal or external elements (Cohen and Nycz, 2006; Convertini and M. Scalera 2006; Buzzetto-More and Pinhey, 2006 ). The IEEE Learning Object Metadata Standard (IEE) specifies the syntax and semantics of learning object metadata describing levels of detail (aggregation) and learning resource types. The aggregation detail ranges from the smallest elements (raw media data or fragments) to secondly a collection of elements for a lesson, thirdly a collection of lessons or modules for a course and finally a set of courses that lead to a qualification.

\section{A PROPOSAL FOR A HISTORIC VIRTUAL REALITY EDUCATIONAL IMMERSIVE EXPERIENCE}

Game engines can be applied to make two major contributions to architectural conservation: they can allow a low-cost method of making an HBIM model more easily accessible to actors in the building industry; and they can be used for educational purposes to facilitate dissemination of knowledge of cultural heritage, particularly in museological applications.

With regards to the first application, BIM software while being incredibly useful as a database of all information pertinent to a building, requires highly trained technicians in order to manage the information in a practical way. This becomes a detriment when considering that insights produced from analysis of a sophisticated BIM model are not easily accessible to all actors in the building industry. Exporting a BIM model into a game engine allows for a packaging of BIM data that can be used in a simplified and more intuitive manner, as has been explored by Edwards, Li, and Wang. Indeed, it is the nature of interactive videogame applications to be intuitive to the user quickly upon assuming controls. A packaged 'game file' is designed to execute in a standalone fashion, requiring no additional proprietary software installed on the end-users computer system. Various novel applications of this method are underway, notably using the BIM model of a new hospital design to train staff to conduct procedures in a new hospital layout. Further investigation into IFC file compatibility may lead to greater efficiency of the workflow between BIM software and game engines. Current mainstream industry packages include Unity3D and the Unreal Engine which allow for highly developed workflows and community support, but recent game engine software like Autodesk's Stingray package hold promise for greater interoperability of IFC files.

With regards to educational applications, game engines can give public access to information that is usually restricted specialists as argued by Yan and Liu. Places and objects that are normally kept behind locked doors and glass cases for necessities of conservation, can have virtual models produced which allow for spaces to be experienced, and even objects to be touched and handled. In essence, museological applications of game engines have the potential to do away with the unfortunate condition of 'do not touch'.

Finally, with regards to both building and museological applications, the nature of videogame engines are scalable and multiplatform, meaning that historical artifacts can potentially be viewed on a variety of systems with different performance capabilities, from tablets to sophisticated virtual reality workstations (Hilfert and König, 2016; Edwards and Bin Wang 2015; Merschbrock, Lassen, and Tollnes2014; Yan, and Liu, 2007).

If Historic Building Information Modelling (BIM) is incorporated into the design for Virtual learning in building conservation, it offers a very different experience from classroom-based learning. In the case of this project the final objective is to create a Web based HBIM which will be accessible from desktop personal computers, laptops and hand held devices, to enable individual and group based student learning. The learning software will simulate realistic case study scenarios based on site surveys of the historic construction.

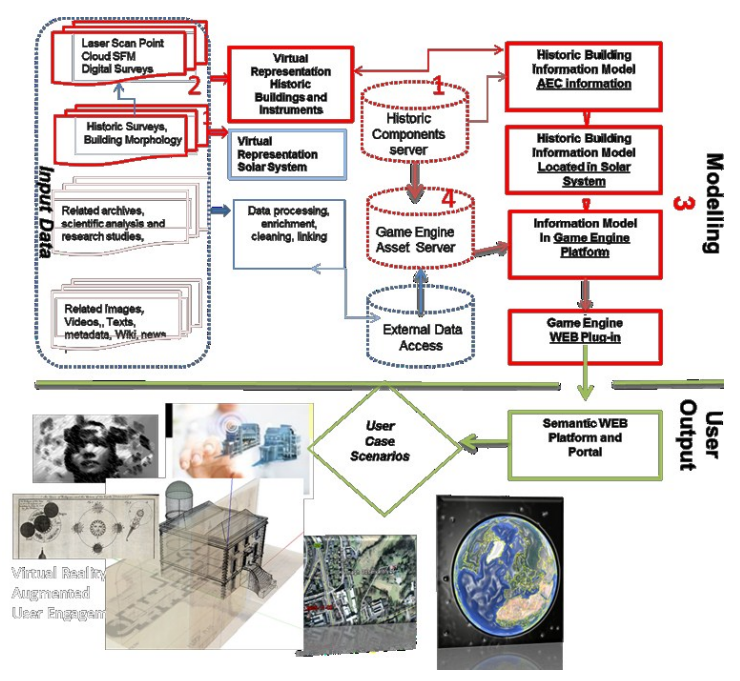

Figure 14: Systems Architecture for Virtual Reality Immersive Model of Armagh Observatory

\section{REFERENCES}

Akpinar, Y., Validation of a Learning Object Review Instrument: Relationship between Ratings of Learning Objects and Actual Learning Outcomes, Interdisciplinary Journal of ELearning and Learning Objects Volume 4, 2008 Editor: Heinz Dreher

Apolo Mapping, https://apollomapping.com/how-to/creatingkmz-file-google-earth

Baik, A, Alitany, A, Boehm, J \& Robson, S 2014, 'JEDDAH HISTORICAL BUILDING INFORMATION MODELING "JHBIM"- OBJECT LIBRARY ', ISPRS Annals of the Photogrammetry, Remote Sensing and Spatial Information Sciences, vol. II-5, pp. 41-7 
Bannan-Ritland, B., Dabbagh, N. \& Murphy, K. (2002) Learning object systems as constructivist learning environments: related assumptions, theories, and applications, in: D. A. Wiley (Ed.) The instructional use of learning objects (Bloomington, IN, Agency for Instructional Technology and Association for Educational Communications \& Technology), $61-97$.

Bennett, J.A. 1990. Church, State and Astronomy in Ireland 200 years of Armagh Observatory,

Boeykens, S 2011, 'Using 3D Design software, BIM and game engines for architectural historical reconstruction', paper presented to the CAAD Futures .

Boeykens, S, Himpe, C \& Martens, B 2012, 'A Case Study of Using BIM in Historical Reconstruction - The Vinohrady synagogue in Prague', paper presented to The 30th International Conference on Education and research in Computing Aided Architectural Design in Europe

Brumana, R, Oreni, D, Raimondi, A, Georgopoulos, A \& Bregianni, A 2013, 'HBIM for Documentation, Dissemination and Management of Built Heritage. The Case Study of St. Maria in Scaria d'Intelvi', paper presented to International Journal of Heritage in the Digital Era

Butler, C.J. and Hoskins, M., 1987. The archives of Armagh Observatory, Journal for the History

Buzzetto-More, N., and Pinhey, K., Guidelines and Standards for the Development of Fully Online Learning Objects, Interdisciplinary Journal of Knowledge and Learning Objects 2006(2), 96-104

Carbonari, G, Stravoravdis, S \& Gausden, C 2015, 'Building information model implementation for existing buildings for facilities management: a framework and two case studies', WIT Transactions on The Built Environment

Cernea D. A., Del Moral E., \& Labra J. E. (2008). SOAF: Semantic indexing system based on collaborative tagging. Interdisciplinary Journal of E-Learning and Learning Objects, $4,137-149$

Chenaux, A, Murphy, M, Keenaghan, G, Jenkins, J \& McGovern, E 2011, 'Combining a Virtual Learning Tool and Onsite Study Visits of Four Conservation Sites in Europe

Chevrier, C, Charbonneau, N, Grussenmeyer, P \& Perrin, J-P 2010, 'Parametric Documenting of Built Heritage: 3D Virtual Reconstruction of Architectural Details', International Journal of Architectural Computing 8(2).

Cohen, E. \& Nycz, M., Learning objects e-learning: An informing science perspective. Interdisciplinary Journal of Knowledge and Learning Objects, 2006(2), 23-24.

Curl, J.S., 1992. Classical Architecture, Batsford, London McParland, E. 1969. Francis Johnston, Architect, 1760-1829. Quarterly Bulletin

David A. Wiley and Sandie H. Waters , Scoping and Sequencing Educational Resources and Speech Acts: A Unified Design Framework for Learning Objects and Educational
Discourse, Interdisciplinary Journal of Knowledge and Learning Objects Volume 1, 2005

David Porter Joanne Curry Bill Muirhead Nick Galan, 2002, A Report on Learning Object Repositories Review and Recommendations for a Pan-Canadian Approach to Repository Implementation in Canada for CANARIE Inc.

De Luca, L 2011, 'Methods, formalisms and tools for the semantic-based surveying and representation of architectural heritage', Applied Geomatics 6(1866).

Eastman, C, Teicholz, P, Sacks, R \& Liston, K 2011, BIM Handbook: A Guide to Building Information Modeling for Owners, Managers, Designers, Engineers and Contractors, 2nd Edition, Wiley

Edwards, Gareth, Haijiang Li, and Bin Wang. "BIM based collaborative and interactive design process using computer game engine for general end-users." Visualization in Engineering 3, no. 1 (2015): 4.

Fai, S \& Rafeiro, J 2014, 'Establishing an Appropriate Level of Detail (LoD) for a Building Information Model (BIM) - West Block, Parliament Hill', Ottawa, Canada, ISPRS Annals of the Photogrammetry, Remote Sensing and Spatial Information Sciences .

Fai, S \& Sydor, M 2013, 'Building Information Modelling and the documentation of architectural heritage: Between the 'typical' and the 'specific", paper presented to the Digital Heritage International Congress (Digital Heritage ).

Fai, S, Graham, K, Todd Duckworth, Wood, N \& Attar, R 2011, 'Building Information Modeling and Heritage Documentation', paper presented to CIPA 2011 Conference proceedings: XXIIIrd International CIPA Symposium

Georgian Society, Volume 12. Robinson, T.R., 1829-1832. Astronomical Observations made at the Armagh Observatory, vols 1- 3, London

Martin, A. and McGovern, E., 2012. An evaluation of the performance of network RTK GNSS services in Ireland. International Federation of Surveyors (FIG) Working week 6th10th May 2012. Rome, Italy

Mason, J., Pegler, C., Weller, M., JALN CASE STUDY 97 A LEARNING OBJECT SUCCESS STORY JALN Volume 9, Issue 1, March 2005

Merschbrock, Christoph, Ann Karina Lassen, and Tor Tollnes. "Integrating BIM and gaming to support building operation: the case of a new hospital." (2014).

Mohan, P., Learning Object Repositories, Proceedings of the 2005 Informing Science and IT Education Joint Conference, Flagstaff, The University of the West Indies, St. Augustine, Trinidad and Tobago Arizona, USA - June 16

Murphy, M, McGovern, E \& Pavia, S 2009, 'Historic building information modelling (HBIM)', Structural Survey, vol. 27, no. 4, pp. 311-27.

Murphy, M, McGovern, E \& Pavia, S 2013, 'Historic Building Information Modelling - Adding intelligence to laser and image based surveys of European classical architecture', ISPRS 
Journal of Photogrammetry \& Remote Sensing, vol. 76, pp. 89102. Observatory, Dublin. of Astronomy Volume 18,, 295-307.

Oreni, D, Brumana, R, Della Torre, S, Banfi, F, Barazzetti, L \& Previtali, M 2014, 'Survey turned into HBIM: the restoration and the work involved concerning the Basilica di Collemaggio after the earthquake (L'Aquila)', ISPRS Ann. Photogramm. Remote Sens. Spatial Inf. Sci ., vol. II-5, pp. 267-73.

Robinson, T.R. and Dreyer, J.L.E., 1886. Second Armagh Catalogue of 3300 stars for the epoch 1875, Dublin. Robinson, T.R., 1859. Places of 5,345 stars observed from 1828 to 1854 at the Armagh

Said Hadjerrouit ,Applying a System Development Approach to Translate Educational Requirements into E-Learning, Interdisciplinary Journal of Knowledge and Learning Objects Volume 3, 2007

Silva, R. P. D., Silva, T. L. K. D., \& Teixeira, F. G. (2007). Learning objects: an approach in engineering education in a cognitive perspective. In International Conference on Engineering and Education (2007 set. 3-7: Coimbra, Portugal). The moving frontiers of engineering: proceedings [recurso eletrônico]. Arlington, VA: iNEER.

Stephen Downes, Models for Sustainable Open Educational Resources, Interdisciplinary Journal of Knowledge and Learning Objects Volume 3, 2007

Stubbs, R, Bourke, C \& Murphy, D 2015, 'Applying Intelligent Modelling Methodologies, through virtual environments, to the Built Heritage. Historic Waterford as a Case Study', paper presented to CITA BIM Gathering 2015

Susan Smith Nash, Learning Objects, Learning Object Repositories, and Learning Theory: Preliminary Best Practices for Online Courses Interdisciplinary, Journal of Knowledge and Learning Objects Volume 1, 2005

V. N. Convertini, D. Albanese, A. Marengo, V. Marengo and M. Scalera. The osel taxonomy for the classification of learning objects. Interdisciplinary Journal of E-Learning and Learning Objects. 2006(1), 125-138.

Varlamis, I. \& Apostolakis, I. (2006). The present and future of standards for e-learning technologies, Interdisciplinary Journal of Knowledge and Learning Objects, 2, 59-76

Wiley, D.A.The learning objects literature. http://opencontent. org/blog/wp-content/uploads/2007/07/wiley-lo-review-final. pdf. Accessed 19th March 2017

Yan, Wei, and Geqing Liu. "BIMGame: Integrating building information modeling and games to enhance sustainable design and education." In Predicting the Future [25th eCAADe Conference Proceedings] Frankfurt am Main (Germany), pp. 211-218. 2007. 